- Dental practices in Merseyside took part in a programme to improve accessibility.

- Disability awareness training can help understanding of disabled people's needs and break

down some barriers. Attitudes are just as important as physical premises in improving access.

- Disability audits highlighted some simple and inexpensive changes that practices could make to improve accessibility

- The paper gives examples of simple changes that practices can consider.

\title{
Disability Part 3: Improving access to dental practices in Merseyside
}

\author{
D. M. Edwards ${ }^{1}$ A. J. Merry ${ }^{2}$ and R. Pealing ${ }^{3}$
}

\begin{abstract}
Several Merseyside dental practices took part in disability access audits of practice premises and practice staff took part in disability awareness training. Grants were awarded to part-fund improvements to practice facilities in line with the recommendations in the audit reports. The dental teams reported that the awareness training was very valuable and many common issues arose from the audits. Access for disabled people needs to be considered in all practice developments to ensure that dental practices comply with Part III of the Disability Discrimination Act by 2004.
\end{abstract}

The first paper in this series outlined how the Disability Discrimination Act affects dental practices. ${ }^{1}$ The second paper reported on a baseline survey of dental practices in North Merseyside, which showed that although most practices were treating disabled patients few dentists described their practices as accessible. ${ }^{2}$ This paper describes the steps that have been taken within Merseyside to address this issue and some of the results.

\section{Methods}

In November 2000 Merseyside Health Action Zone (HAZ) funded a programme to improve the accessibility of dental practices for disabled people. This was in line with the HAZ goals of reducing social exclusion, reducing inequalities and modernising health services. Additional matched funding was made available from the local health authorities and primary

\footnotetext{
${ }^{1 *}$ Director of Public Health, ${ }^{2}$ Specialist Registrar in Dental, ${ }^{3}$ Oral Health Facilitator, Public Health, North Liverpool Primary Care Trust, Newhall Campus, Longmoor Lane, Liverpool L10 1LD

${ }^{*}$ Correspondence to: Dympna Edwards

E-mail:dympna.edwards@northliverpoolpct.nhs.uk
}

\section{Refereed Paper}

Received 16.01.02; Accepted 23.05.02

$\odot$ British Dental Journal 2002; 193: 317-319 care groups/trusts. The aim of the programme was to increase the accessibility of dental practices for disabled people. A fixed amount of grant funding was available for practices in each primary care group area.

There were three aspects to the programme: disability awareness training, an access audit of the practice premises and a grant for physical improvements to the practice and/or equipment to increase access. We wrote to all the dental practices in Merseyside inviting them to take part. Some practices had either an audit or training. Those who received a grant were required to undergo some training, had an audit of their practice with some recommendations and had a follow-up audit 9 months later to assess the degree of change.

\section{FINDINGS}

\section{Training}

The Disability Advisor of a local NHS Trust ran a number of half-day disability awareness training workshops. The response to the training was so positive that further courses were commissioned and a total of eight training courses have taken place at the time of writing. Training sessions were evaluated using an anonymous question- naire. When asked to identify the most useful aspect of the course many participants felt that the training had given them a better understanding of disability, how the Disability Discrimination Act affected their practices and practical steps that they could consider. Other comments included:

'It taught me to think about my attitudes' 'It was good to hear things from a disabled person's point of view'

'I found myself talking to a disabled person as a 'normal person' - positively'

The evaluation also identified a need for more specific courses such as British Sign Language training, which are being provided through the primary care trusts along with other healthcare staff.

\section{Audits}

Twenty-seven practices underwent an access audit carried out by a company specialising in this area. Audits consisted of a visit to the practice lasting between 30-45 minutes and a discussion with the practice principal or manager.

Each practice was sent a report in two sections. The first section was a two-page summary report relating to their practice and outlining what was done well, what could be improved with little effort and 
what improvements could be planned for. The second section contained the merged and anonymised findings from all the audited practices. This explained why the issues identified were important and how they could be addressed. The advantage of having two sections was that practitioners could see at a glance what needed to be done without being overwhelmed by detail. The reports also provided further information to help practices make the necessary changes.

A number of common issues emerged from the audits. These are outlined below:

\section{Attitudes of staff}

The audit team reported marked differences in the attitudes and approaches of practices whose staff had been on the disability awareness training compared with those who had not yet had training. Practices who had had training were more willing to consider a wider range of changes as opposed to just the physical barriers. For example, they were receptive to suggestions about the position of magazine racks or layout of chairs in the waiting room. They were also willing to consider how their service needed to adapt to meet patients' needs, for example how a deaf patient is called in from the waiting room.

It was important that all staff in the practices were trained in disability awareness to get a co-ordinated approach. In some practices staff who had been trained had made changes that were reversed by other staff who had not been trained and did not understand why the changes were needed. The audit team reported that the practices with more positive attitudes were also those who had made most progress in implementing the findings of the audits.

\section{Health and safety issues}

Many of the recommendations related to basic health and safety issues that affect everyone. Common problems included doormats not being level with the floor causing a tripping hazard, coffee tables with sharp edges placed in front of seating rather than beside seating and the absence of radiator guards.

The needs of disabled people were not always considered in safety procedures. Fire alarms could be wired to the lighting in the waiting room to flash on and off when the alarm went, giving a visual as well as audio alarm.

\section{Parking}

Many practices had designated parking but didn't have a disabled space marked. Gravel on paths makes it difficult for patients to use wheelchairs and pushchairs. Practices can contact their local authority to ensure that dropped kerbs are placed to make the external environment more accessible.

\section{Ramps and handrails}

The lack of adequate ramps and handrails was a common finding. Ideally ramps should be at the main entrance (rather than at the back door only) and the fire escape should also be ramped. The maximum gradient for a ramp is $1: 12$ and there should be a horizontal section at the top. Many practices did have handrails but these often didn't extend beyond the bottom of the steps making them difficult for people to grasp.

Although many practices had toilet facilities that were not fully accessible they could often be improved by the use of handrails.

\section{Reception}

Many practices had high reception desks that are inaccessible to wheelchair users and shorter people. These ideally should be split height and the lower section should be about $1.1 \mathrm{~m}$ high with a sufficient overhang to enable a wheelchair user to reach the desk. Where this is not possible a clipboard makes it easier for patients who cannot reach the desk to fill in forms.

Many practices had doorbells that were too high for wheelchair users to reach. The ideal height is around $1 \mathrm{~m}$ from the ground. Providing tonal contrast between the doorbell and the surrounding wall will help visually impaired people.

\section{Seating in the waiting room}

A choice of seat styles, including some with higher backs and arms for support, makes a waiting room accessible for more people. Ideally there should be enough space, including circulation space for a wheelchair user to wait in comfort. The audits found that seating was not always ideal for disabled people, and in a few cases practices had recently installed new chairs with a uniform style and height, often without armrests. Although these look neat they can reduce access for some, for example, older people or those with arthritis.

\section{Hearing impairment}

Practices often had background music in reception and surgery areas. This can make it difficult for patients with hearing difficulties to differentiate speech and should be avoided.

None of the practices had a hearing induction loop installed - yet these can significantly assist people who use hearing aids and could be especially useful when masks are worn. Induction loops are relatively cheap, for example a fixed loop at reception and portable loop for use in the surgeries would cost around £200.
Very few practices used a text phone or the free BT Typetalk service, which enable deaf and hearing-impaired people to communicate more easily by telephone.

\section{Visual impairment}

Tonal contrast of the décor in waiting rooms, corridors and surgeries was often poor. A contrast, for example between the door and its frame and handle, makes it easier for a partially sighted person to identify these features and get around safely.

Practice information (leaflets, appointment cards etc) was typically inaccessible for visually impaired people and it was unusual for the information to be available in alternative formats. Many visually impaired people find large print leaflets or information on audiotape very useful and some find it easier to communicate by email. Practice information can be very easily and cheaply produced in large print using computers or photocopiers. Ideally practices should also be prepared to produce information on audiotape or on computer floppy disc. Many patients can use information on computer disc using voiceactivated software or can print it in Braille or Moon (similar to Braille).

\section{BUILDING REGULATIONS}

The standards for full accessibility are higher than those outlined in part M Building Regulations. For example, the building regulations recommend a minimum door width of $800 \mathrm{~mm}$ whereas guidelines for full access suggest that doors should be at least $900 \mathrm{~mm}$ wide. So in order to comply fully with the Disability Discrimination Act, dentists should be aware that following the Building Regulations might not ensure full access.

\section{ACCESSIBILITY GRANTS}

There were more applicants from larger practices in affluent areas than singlehanded practices and those in more deprived areas.

A total of $£ 100,000$ was allocated to 27 practices for practice improvements. These grants predated the "modernisation funding' and focused on small achievable changes. The emphasis was on improving access for people with a range of impairments. This meant that practices that were not wheelchair accessible could still make improvements to make their practices more accessible for patients with other impairments.

Many of the changes were simple and quickly implemented. For example, installing hearing induction loops or adding seating with armrests in the waiting room. Some of the structural changes took longer or proved to be more compli- 
cated than initially envisaged. Many of the practitioners were able to combine the recommended changes with developments they were making with modernisation funding. ${ }^{3}$

\section{FUTURE PLANS}

The disability awareness training programme is continuing so that more practices can take part and we envisage that a rolling programme of regular training will be developed. A second group of 24 practices had an access audit to inform changes that they were planning using 'modernisation funding' available in $2001 / 2$. A self audit tool is being developed for practices to be taken forward as part of a clinical governance programme.

\section{DISCUSSION}

Although most general medical practices have undergone access audits and developments to improve accessibility in the past few years, general dental practices have not usually been involved. As a result many disabled people may be faced with inaccessible buildings and services when they try to visit their dentist.

Attitudes and the way services are organised are as important as physical barriers. All practices can make services more accessible even if they are not accessible for wheelchair users. The audits identified some common barriers that could easily have been prevented with a little awareness and foresight. Disability awareness training can help to overcome some of these barriers.

Accessibility is not a new issue. The British Society for Disability and Oral Health produced guidelines on access in 1989. ${ }^{4}$ The Disability Rights Commission ${ }^{5}$ can provide advice to practices. Many Local Authorities have Access Officers who can advise on improving access to premises. Merseyside Local Authorities have produced practical guidelines for small businesses to make premises and services more accessible. $^{6}$
The Disability Rights Commission strongly recommends that all service providers, including dental practices, have an access audit. These are available from a range of commercial organisations. We would advise that dentists ask for recommendations and references as the quality and price of advice can vary widely. As many Primary Care Trusts and general medical practices have commissioned audits these may be a good source of information on where to go locally.

Although practices can ask individual patients about barriers to access, they should also have an access audit from an independent agency to ensure that all barriers are identified and addressed. This is important because if the practice presents barriers to some disabled people those people will not become patients of the practice and so those barriers will not be identified. Relying alone on reports from individual patients could also lead to changes being made that make access more difficult for other patients and correcting inadequate alterations may increase costs.

There was a better response to the programme from two of the health districts that traditionally have had a number of health authority funded schemes and perhaps this affected the response. Anecdotal feedback from practitioners who did not apply for the scheme was interesting. Some practitioners assumed that since their practice was not and could not easily become wheelchair accessible that there was little they could do to improve accessibility. However, as only 5\% of disabled people are permanent wheelchair users this indicates the need for disability awareness training. The audit reports have highlighted the range of improvements that can be made to increase access to people with a wide range of disabilities.

Other practitioners were worried that the existence of an audit report stating in black and white that their practice was not accessible would make them more vulnerable under the Disability Discrimi- nation Act. In fact, the reverse is true. If practitioners can show that they have looked at their practices and made reasonable steps to make them accessible then they are in a stronger position to counteract any potential litigation. Dentists as service providers are obliged by the Act to make reasonable steps to improve access to their services. If full access is not possible then alternative arrangements for treatment (being seen in another practice either by the same dentist or by a colleague) may be appropriate.

\section{CONCLUSION}

Part III of the Disability Discrimination Act will come into force in 2004 and by then service providers must have taken reasonable steps to remove any physical barriers that prevent access. Dentists need to be aware of their responsibilities under the Disability Discrimination Act and should prepare themselves to meet these responsibilities in order to avoid possible litigation. Dental practice staff were enthusiastic about the disability awareness training and it provided a broader understanding of disability. Access can often be improved for little or no cost. An access audit can highlight hidden barriers to care. Where major alterations are required to provide full access these are necessary only if reasonable.

1. The Disability Discrimination Act 1995. London: HMSO, 1995.

2. Edwards D M, Merry A J. Access to Dental Services for Disabled People. A Questionnaire Survey of Dental Practices in Merseyside. Br Dent J2002; 193: 253255.

3. Modernising NHS dentistry: implementing the NHS plan. Department of Health. September,2000.

4. The British Society for Disability and Oral Health. 1989, Annual report.

5. Disability Rights Commission: Telephone 08457622 633, Fax 08457778 878, Textphone 08457622644. DRC Helpline, Freepost MID 02164, Stratford-uponAvon, CV37 9B.

6. Merseyside Local Authorities. Merseyside Code of Practice on Access and Mobility (October 2000). 